
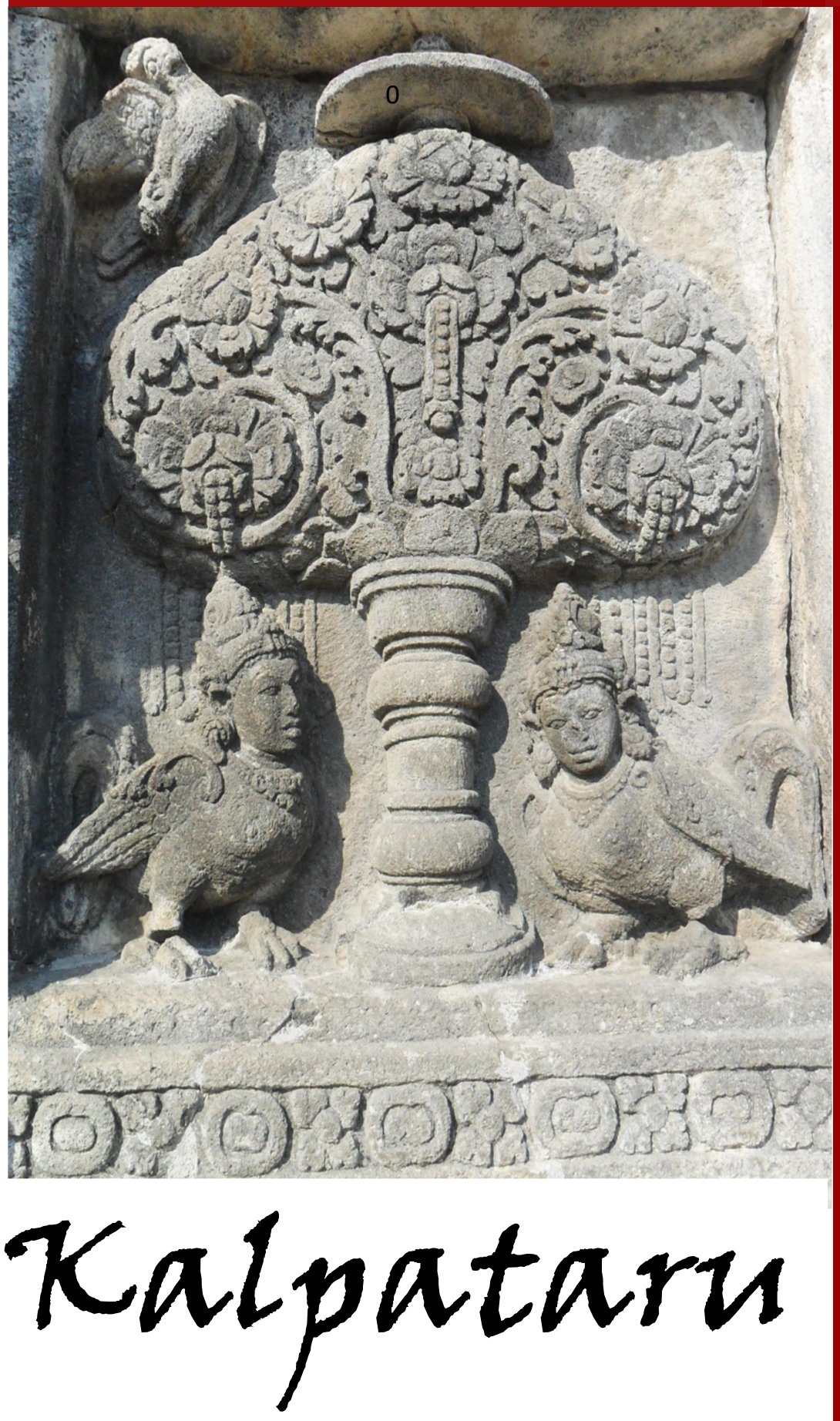

\author{
JURNAL SEJARAH DAN \\ PEMBELAJARAN SEJARAH
}

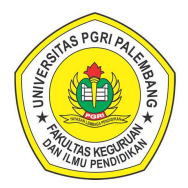

Program Studi Pendidikan Sejarah Jurusan Pendidikan IPS

Fakultas Keguruan dan IImu Pendidikan Universitas Persatuan Guru Republik Indonesia Palembang
Pengaruh Model Pembelajaran Student Facilitator and Explaining Terhadap Hasil Belajar Siswa Pada Mata Pelajaran Sejarah Kelas $X$ di SMA Negeri 3 Palembang

Sarinah, Nur Ahyani, Ahmad Zamhari

Pengaruh Model Pembelajaran Berbasis Masalah (PBM) Terhadap Hasil Belajar Siswa Pada Mata Pelajaran IPS Terpadu (Sejarah) Kelas VIII di SMP Negeri 2 Palembang

Neka Dapistri, Nur Ahyani, Ahmad Zamhari

Penerapan Media Pembelajaran Menggunakan Google Earth Dalam Materi Kondisi Masyarakat Indonesia Pada Masa Penjajahan Terhadap Hasil Belajar Siswa Pada Mata Pelajaran IPS Terpadu di SMP Quraniah Palembang

Tri Nur Ariani, Eva Dina Chairunisa, Ida Suryani

Perkembangan Sosial Budaya Suku Jawa di Desa Kapasan Tegalrejo BK $X$ Kecamatan Belitang Kabupaten Ogan Komering Ulu Timur Sebagai Sumber Pembelajaran Sejarah di SMA Muhammadiyah 2 Karang Tengah

Ratna Puspita Dewi, Sukardi, Mirza Fansyuri

Pengembangan E-Modul Pembelajaran Sejarah Tokoh-Tokoh Pembangunan

Susi Susanti, Eva Dina Chairunisa

Peran Pendidikan Sejarah Dalam Membentuk Karakter Bangsa

Sukardi, Jeki Sepriady

Sejarah Pengajaran Mantra Melayu di Tengah Perubahan Masyarakat Besemah Muhamad Idris, Eva Dina Chairunisa, Jeki Sepriady

Pengembangan Media Audio Visual Sejarah Kolonialisme Barat di Indonesia Materi Benteng Marlborough Bengkulu Hamza Kurniawan 


\section{Kalpataru}

Jurnal Sejarah dan Pembelajaran Sejarah

Volume 6, Nomor 2, Desember 2020

\section{Chief Editor}

Drs. Sukardi, M.Pd.

\section{Editor}

Dr. Muhamad Idris, M.Pd.

Eva Dina Chairunisa, M.Pd.

Jeki Sepriady, S.Pd.

\begin{tabular}{ll}
\multicolumn{2}{c}{ Reviewer } \\
Dr. Tahrun, M.Pd. & (Universitas PGRI Palembang) \\
Drs. Supriyanto, M.Hum. & (Universitas Sriwijaya Palembang) \\
Dra. Retno Purwati, M.Hum. & (Balai Arkeologi Sumatera Selatan) \\
Dr. Nor Huda Ali, M.Ag., M.A. & (Masyarakat Sejarawan Indonesia Sumsel) \\
Dr. Budi Agung Sudarman, S.S., M.Pd. & (Balai Bahasa Provinsi Sumatera Selatan) \\
Dr. Purmansyah, M.A. & (Universitas Muhammadiyah Palembang)
\end{tabular}

Alamat Redaksi

Program Studi Pendidikan Sejarah

Fakultas Keguruan dan IImu Pendidikan Universitas PGRI Palembang

Telp. 0711-510043

Email: jurnalkalpatarusejarah@gmail.com

Website: https://jurnal.univpgri-palembang.ac.id/index.php/Kalpa 


\section{Kalpataru}

JURNAL SEJARAH DAN

PEMBELAJARAN SEJARAH

Terbit dua kali setahun pada Juli dan Desember

Diterbitkan oleh:

Program Studi Pendidikan Sejarah

Jurusan Pendidikan IPS

Fakultas Keguruan

dan IImu Pendidikan

Universitas PGRI Palembang

\section{Gambar Cover:}

Pohon Kalpataru

Candi Prambanan

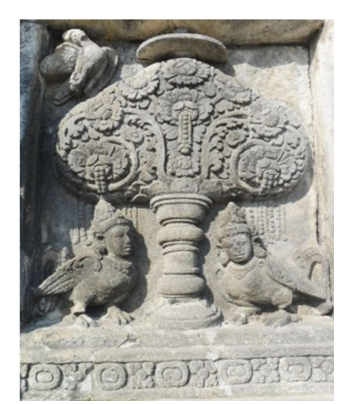

Koleksi: Muhamad Idris 


\section{DAFTAR ISI}

Pengaruh Model Pembelajaran Student Facilitator and Explaining Terhadap Hasil Belajar Siswa Pada Mata Pelajaran Sejarah Kelas X di SMA Negeri 3 Palembang

Sarinah, Nur Ahyani, Ahmad Zamhari 83-89

Pengaruh Model Pembelajaran Berbasis Masalah (PBM) Terhadap Hasil Belajar Siswa Pada Mata Pelajaran IPS Terpadu (Sejarah) Kelas VIII di SMP Negeri 2 Palembang

Neka Dapistri, Nur Ahyani, Ahmad Zamhari..... 90-95

Penerapan Media Pembelajaran Menggunakan Google Earth Dalam Materi Kondisi Masyarakat Indonesia Pada Masa Penjajahan Terhadap Hasil Belajar Siswa Pada Mata Pelajaran IPS Terpadu di SMP Quraniah Palembang

Tri Nur Ariani, Eva Dina Chairunisa, Ida Suryani $96-101$

Perkembangan Sosial Budaya Suku Jawa di Desa Kapasan Tegalrejo BK X Kecamatan Belitang Kabupaten Ogan Komering Ulu Timur Sebagai Sumber Pembelajaran Sejarah di SMA Muhammadiyah 2 Karang Tengah

Ratna Puspita Dewi, Sukardi, Mirza Fansyuri. $102-109$

Pengembangan E-Modul Pembelajaran Sejarah Tokoh-Tokoh Pembangunan Pacsa Kemerdekaan di Sumatera Selatan

Susi Susanti, Eva Dina Chairunisa 110-113

Peran Pendidikan Sejarah Dalam Membentuk Karakter Bangsa

Sukardi, Jeki Sepriady $114-117$

Sejarah Pengajaran Mantra Melayu di Tengah Perubahan Masyarakat Besemah Muhamad Idris, Eva Dina Chairunisa, Jeki Sepriady..... 118-127

Pengembangan Media Audio Visual Sejarah Kolonialisme Barat di Indonesia Materi Benteng Marlborough Bengkulu

Hamza Kurniawan. 128-135 


\title{
PERAN PENDIDIKAN SEJARAH DALAM MEMBENTUK KARAKTER BANGSA
}

\author{
Sukardi \\ Dosen Program Pendidikan Sejarah FKIP Universitas PGRI Palembang \\ Email: sukardi_si@univpgri-palembang.ac.id \\ Jeki Sepriady \\ Guru Sejarah di SMA Maitreyawira Palembang \\ Email: jeki.indonesia@gmail.com
}

\begin{abstract}
ABSTRAK
Pembelajaran sejarah pada dasarnya merupakan proses pendidikan yang merupakan usaha pengembangan daya manusia agar dapat membangun diri dan bersama sesama dapat membudayakan alam dan membangun masyarakat. Sejarah merupakan salah satu mata pelajaran yang berpengaruh terhadap pembangunan karakter bangsa. Penelitian ini mengangkat tema peran pendidikan sejarah dalam membentuk karakter bangsa. Tujuan penelitian ini untuk mengetahui bagaimana peran pendidikan sejarah dalam membentuk karakter bangsa. Hasil penelitian ini menggambarkan bahwa pendidikan sejarah sangat berpengaruh dalam meningkatkan karakter bangsa. Karena di dalam materi-materi sejarah itu terdapat pesan-pesan yang dapat meningkatkan jiwa nasionalisme dan patriotisme, sehingga dapat membentuk karakter bangsa.
\end{abstract}

Kata Kunci: Pendidikan Sejarah, Karakter.

\section{PENDAHULUAN}

Pendidikan merupakan suatu sistem yang teratur dan mengemban misi yang cukup luas yaitu segala sesuatu yang bertalian dengan perkembangan fisik, kesehatan, keterampilan, pikiran, perasaan, kemauan, sosial sampai kepada masalah kepercayaan atau keimanan. Hal ini menunjukkan bahwa sekolah sebagai suatu lembaga pendidikan formal mempunyai suatu muatan beban yang cukup berat dalam melaksanakan misi pendidikan tersebut. Lebih-lebih kalau dikaitkan dengan pesatnya perubahan zaman dewasa ini yang sangat berpengaruh terhadap anak-anak didik dalam berfikir, bersikap dan berperilaku, khususnya terhadap mereka yang masih dalam tahap perkembangan dalam transisi yang mencari identitas diri (Departemen Agama Kendali Mutu, 2001:10).

Indonesia merupakan salah satu negara berkembang di dunia yang masih memiliki permasalahan penting, seperti yang dijelaskan Tilaar dalam Yasa (2013:113), yaitu: 1) ketegangan antar kelompok didalam masyarakat; dan 2) merosotnya hak asasi manusia dalam masyarakat. Hal tersebut diiringi dengan semakin merosotnya penghargaan terhadap hak asasi manusia, seperti banyaknya pembunuhan, pelanggaran kebebasan berpendapat, kebebasan beragama dan lainnya. Kesan bangsa Indonesia yang ramah dan penuh dengan toleransi seperti yang dipublikasikan melalui media massa sudah mulai sirna dan bangsa Indonesia nyaris kehilangan jati dirinya, kini bangsa ini seakan menjadi bangsa sakit yang harus segera diobati.

Jati diri yang hilang yaitu karakter akan bangsa yang ramah dan penuh toleransi itu perlu ditumbuhkan kembali. Salah satu caranya adalah menggali kembali memori masa lalu. Hal ini sejalan dengan pemikiran Kartodirdjo (2017:xiii) bahwa proses national building for national identity menuntut rekontruksi sejarah yang akan mewujudkan kristalisasi identitas bangsa Indonesia. Dengan kata lain penting untuk memahami sejarah bangsa bagi pembangunan. Maka tepatlah pernyataan salah seorang founding father bangsa ini Bung Karno tentang "Jas Merah" (jangan sekali-kali melupakan sejarah). Beliau mengingatkan kepada generasi bangsa ini untuk selalu mengingat masa lalu atau sejarah bangsa ini. Itulah model karakter yang bisa dijadikan sebagai teladan, ditengah hilangnya teladan 
dalam kehidupan sekarang ini (Yasa, 2013:114).

Berbicara soal permasalahan pendidikan, kita dihadapkan pada dimensi praktis pedagogi, yaitu dimensi teknis (bagaimana caranya) dan dimensi normatif (bagaimana seharusnya), yang pertama menyangkut berbagai strategi, proses serta tindakan untuk mengembangkan dan memfungsikan pendidikan dalam masyarakat secara optimal dalam mencapai tujuan yang telah ditetapkan secara nasional. Selanjutnya, yang kedua meliputi berbagai kebijakan yang berusaha merumuskan nilai-nilai kependidikan sebagai landasan mewujudkan cita-cita bersama baik dalam skala mikro (keluarga/masyarakat) maupun skala makro/kehidupan berbangsa (Widja, 2009:1).

Di satu sisi, pendidikan di Indonesia belum sepenuhnya menjawab persoalan tersebut, dengan kata lain, pendidikan kita belum berhasil membentuk generasi muda yang unggul dan berkarakter. Masih banyak pekerjaan rumah yang harus kita lakukan untuk meningkatkan kualitas pendidikan. Hilangnya sebagian karakter peserta didik itu dikarenakan oleh banyak faktor, baik karena faktor internal ataupun karena faktor lingkungan masyarakat.

Sejarah merupakan salah satu mata pelajaran yang diharapkan dapat memperbaiki pendidikan di Indonesia, sehingga dapat menumbuhkan karakter peserta didik dan membentuk generasi muda yang unggul.

\section{PEMBELAJARAN SEJARAH}

Pembelajaran sejarah pada dasarnya merupakan proses pendidikan yang merupakan usaha pengembangan daya manusia agar dapat membangun diri dan bersama sesama dapat membudayakan alam dan membangun masyarakat. Agar dapat mencapai hasil yang optimal, maka dibutuhkan kesadaran sejarah, yaitu suatu sikap yang memberikan kemampuan untuk memahami kepribadian nasional secara cepat. Dalam mencapai tujuan tersebut dapat menggunakan sarana pembelajaran (Kartodirdjo, 2017:6). Proses pembelajaran sejarah mengandung dua tujuan, yaitu pengetahuan eksplisit dan pengetahuan implisit. Pengetahuan eksplisit berkaitan dengan perolehan pengetahuan dan keterampilan sedangkan pengetahuan implisit berkaitan dengan perolehan keterampilan berpikir, sikap (Kartodirdjo, 2017:15).

Pembelajaran sejarah diharapkan menyisipkan pengajaran karakter didalam materinya, penyisipan karakter dalam pembelajaran sejarah merupakan hidden curicullum. Karakter yang diajarkan dalam pembelajaran sejarah hendaknya harus sesuai dengan nilai relegius dan nilai budaya yang dianut peserta didik, guru, lembaga, masyarakat dan negara. Pengajaran karakter merupakan tanggung jawab bersama guru di sekolah, masyarakat dan keluarga. Pengajaran karakter tidak bisa diserahkan hanya pada pihak sekolah, namun harus terjadi sinergi yang kuat antara ketiga unsur pendidikan tersebut. Dalam pembelajaran karakter di sekolah, guru dapat memanfaatkan berbagai sumber pembelajaran, seperti naskah, novel, biografi, autobiografi, buku keagamaan, dan sebagainya.

\section{PENTINGNYA SEJARAH}

Sejarah merupakan salah satu mata pelajaran yang berpengaruh terhadap pembangunan karakter bangsa. Posisi masyarakat yang mulai sedikit demi sedikit melupakan sejarah bangsanya tidak memahami bahwa kesadaran sejarah bangsa penting menjadi aspek pemersatu. Bukti nyata dari mulai terkikisnya rasa nasionalisme atau cinta tanah air dengan merebaknya konflik, baik konflik vertikal dan/ atau horizontal yang terjadi di beberapa daerah.

Ungkapan presiden pertama Republik Indonesia Ir. Sukarno, bangsa yang menghargai jasa-jasa pahlawannya adalah bangsa yang besar adalah benar apa adanya. Tidak mungkin suatu bangsa menjadi maju dan sejahtera jika ia tidak belajar dari sejarah masa lalu bangsanya sendiri. Selama ini, tidak hanya di masyarakat, tapi juga pada tingkat elite, belajar sejarah dianggap membosankan. Peserta didik menganggap pelajaran sejarah menjemukan dan tidak berarti bagi dirinya jika tamat sekolah nantinya. Akibatnya, kita menjadi abai dengan segala sesuatu yang berhubungan dengan sejarah. Bahkan cenderung menderita 
penyakit amnesia sejarah. Ini semua dapat terjadi karena kita sebagai bangsa belum menghargai sejarah sebagai pintu masuk untuk belajar sifat-sifat bijaksana.

Sejatinya kita saat ini sedang mengalami krisis multidimensional yang mengakar pada hilangnya nilai-nilai kebijaksanaan. Tidak ada lagi gotong royong dan toleransi. Kebijakan pemerintah selalu mengalami tentangan dan penolakan masyarakat. Bukan itu saja, sejak otonomi daerah diberlakukan, integritas pemerintah pusat kadang kala diabaikan pemerintah daerah. Jika pemimpin kita mau belajar sejarah, tidaklah sulit untuk membangun bangsa ini. Karena pada dasarnya sejarah mengajarkan kebajikan kepada umat manusia. Sejarah tidak mengajarkan kebohongan dan kemunafikan.

\section{SEJARAH SEBAGAI PEMBENTUK KARAKTER BANGSA}

Sejarah memiliki dimensi luas, ia tidak hanya berhenti di masa lalu. Sejarah adalah segala kejadian di masa lampu yang berdampak luas pada sendi kehidupan masyarakat. Dengan belajar sejarah kita dapat mengambil hikmah positif dari kejadian masa lalu untuk digunakan saat ini demi kehidupan masa depan yang lebih baik. Dalam kaitannya dengan sebagai media pembentuk karakter bangsa, sejarah memiliki peranan yang tidak bisa di anggap sebelah mata.

Nilai karakter yang dapat di ambil memalui sejarah, sebagai berikut:

1. Sejarah mengajarkan nilai-nilai nasionalisme.

2. Sejarah mengajarkan kita untuk mencontoh nilai-nilai perjuangan para pahlawan nasional untuk membebaskan diri dari penindasan bangsa asing .

3. Belajar sejarah juga membentuk karakter bangsa yang peduli terhadap nilai edukasi. Belajar peninggalan sejarah akan mendorong kita untuk menjadi bangsa yang gemar akan penelitian. Dengan penelitian kita dapat mengungkap "misteri" masa lalu dan mengetahui pesan apa yang ingin disampaikan.

4. Belajar sejarah melatih kita untuk memiliki jiwa disiplin dan etos kerja yang tinggi. Belajar sejarah berarti belajar menghargai data sekecil apa pun.

\section{MANFAAT MEMPELAJARI SEJARAH UNTUK KEHIDUPAN MASA KINI}

Sejarah merupakan ilmu pengetahuan yang mempelajari peristiwa pada masa lampau yang berupa peninggalan-peninggalan dan dapat dibuktikan kebenarannya. Mempelajari sejarah dengan mempelajari nilai-nilai luhurnya akan menjadikan generasi-generasi berikutnya lebih menghargai bangsa sendiri (Sepriady, 2018:36).

Manfaat mempelajari sejarah untuk kehidupan masa kini adalah, sebagai berikut:

1. Sebagai sarana mengenal lebih dekat bangsa sendiri dan bangsa-bangsa lain.

Sejarah mengajarkan kita untuk memahami masyarakat dan bangsa sendiri serta juga mengenal bangsabangsa lain. Dengan mempelajari sejarah, kita akan lebih menghargai hal-hal yang bangsa kita miliki.

2. Sebagai panduan moral dan politik.

Sejarah perumusan dasar Negara Indonesia menunjukkan pentingnya sikap kenegarawanan, jiwa besar, penghargaan terhadap perbedaan dan keberagaman, rela berkorban, dan mau berpikir dari sudut pandang orang lain.

3. Memperkokoh identitas bangsa.

Akar sejarah yang dalam dan panjang akan memperkokoh keberadaan, identitas, serta kepribadian suatu bangsa. Dengan demikian, suatu bangsa akan bangga dan mencintai sejarahnya.

4. Latihan berpikir menyeluruh (holistik) dan multiperspektif.

Melatih kita untuk berpikir menyeluruh dan multiperspeksif dalam memandang suatu peristiwa. Suatu peristiwa sejarah tidak sederhana, suatu peristiwa sejarah juga tidak berdiri sendiri, melainkan terkait dengan peristiwa-peristiwa lain sebelumnya.

5. Melatih berpikir diakronik dan sinkronik. Berpikir menggunakan perspektif yang sesuai dengan sejarah.

\section{SIMPULAN}


Sejarah sejatinya bukanlah benda mati. la bangunan "hidup" yang memiliki banyak pesan bijak untuk disampaikan ke banyak orang, terutama kepada generasi muda. Menghargai sejarah itu berarti satu langkah menuju bangsa yang beradab. Hanya dengan cara inilah, mimpi kita menjadi bangsa yang besar dan maju bisa tercapai.

\section{DAFTAR PUSTAKA}

Departemen Agama Kendali Mutu. 2001. Pendidikan Agama Islam. Jakarta: Dirjen Pembinaan Kelembagaan Agama Islam.

Kartodirdjo, Sartono. 2017. Pendekatan IImu Sosial Dalam Metodologi Sejarah. Yogyakarta: Ombak.

Sepriady, Jeki. 2018. Naskah Syair Perang Palembang sebagai Sumber Karakter dalam Pembelajaran Sejarah di SMA Unggul Negeri 4 Palembang. Palembang: Universitas PGRI Palembang.

Widja, I Gde. 2009. Pendidikan Sebagai Ideologi Budaya: Suatu Pengantar ke Arah Pendidikan Kritis. Denpasar: Program Magister (S2) dan Program Doktor S3 Kajian Budaya Universitas Udayana.

Yasa, I Wayan Putra. 2013. "Pembelajaran Sejarah Untuk Mewujudkan Manusia Indonesia Yang Berkarakter". dalam Historia Pedagogia. Volume 2, Nomor 2, November 2013. (112-120). 


\section{KETENTUAN PENULISAN ARTIKEL JURNAL KALPATARU}

1. Naskah berbahasa Indonesia yang disempurnakan bertemakan kesejarah yang meliputi hasil penelitian sejarah, pengajaran sejarah dan penelitian kebudayaan.

2. Naskah harus asli dan belum pernah dimuat dalam media lain. Naskah dapat berupa hasil penelitian/artikel kajian konseptual yang ditulis oleh perorangan dan atau kelompok.

3. Naskah ditulis dengan cara-cara yang sesuai dengan ketentuan penulisan artikel ilmiah menggunakan bahasa Indonesia yang baku, berupa ketikan, beserta soft file dalam CD-RW atau dengan mengirimkan email pada redaksi jurnal Kalpataru dengan alamat jurnalkalpatarusejarah@gmail.com, spasi tunggal, jenis huruf arial narrow ukuran 12, dengan panjang naskah antara 8-15 halaman pada kertas A4.

4. Artikel hasil penelitian memuat:

JUDUL

Nama Penulis

Abstrak

\section{: XXX (HURUF KAPITAL)}

: (disertai jabatan, institusi, dan email)

: (Bahasa Indonesia yang memuat 100-200 kata diikuti kata kunci, dengan jenis huruf arrial narrow dan ukuran huruf 11 serta dicetak miring).

: (memuat latar belakang masalah, tinjauan pustaka secara ringkas, masalah penelitian, dan tujuan penelitian).

\section{B. METODE PENELITIAN}

C. HASIL DAN PEMBAHASAN

D. SIMPULAN : (berisi simpulan).

DAFTAR PUSTAKA : (berisi pustaka yang dirujuk dalam uraian naskah).

5. Artikel Kajian Konseptual memuat:

JUDUL

Nama Penulis

Abstrak

PENDAHULUAN

Sub Judul

Simpulan

DAFTAR PUSTAKA

\section{: XXX (HURUF KAPITAL)}

: (disertai jabatan, institusi, dan email)

: (Bahasa Indonesia yang memuat 100-200 kata diikuti kata kunci, dengan jenis huruf arrial narrow dan ukuran huruf 11 serta dicetak miring.

: (memuat latar belakang masalah, tinjauan pustaka secara ringkas, masalah penelitian, dan tujuan penelitian).

: Sesuai dengan kebutuhan (tanpa numbering).

: (berisi simpulan dan saran).

6. Referensi sumber dalam teks artikel ditulis dengan menggunakan side note, contoh (Jalaludin, 1991:79); sementara penulisan daftar pustaka disusun dengan ketentuan. Nama pengarang. Tahun terbit. Judul (dicetak miring). Kota terbit: Nama Penerbit. Contoh: Koentjaraningrat. 2010. Manusia dan Kebudayaan di Indonesia. Jakarta: Djambatan. Daftar pustaka hanya memuat pustaka/sumber yang dirujuk dalam uraian dan disusun menurut abjad tanpa nomor urut.

7. Naskah yang dimuat akan disunting kembali oleh redaksi tanpa mengubah isinya.

8. Naskah yang ditolak (tidak bisa dimuat) akan dikirim kembali ke penulis dengan pemberitahuan tertulis dari redaksi atau melalui email.

9. Penulis yang naskahnya dimuat akan mendapat 1 (satu) majalah nomor yang bersangkutan.

10.Kontak person: Muhamad Idris (081271498618); Eva Dina Chairunisa (082281267851); Jeki Sepriady (085269261780). 